\title{
PROGRAM PENDIDIKAN MENENGAH UNIVERSAL SEBAGAI PERSIAPAN WAJIB BELAJAR DUA BELAS TAHUN
}

\author{
Subijanto, Philip Suprastowo, Yaya Jakaria, Hendarman, Ponco Waluyo, dan \\ L. Hermin Winigsih \\ Pusat Penelitian Kebijakan Pendidikan dan Kebudayaan, Balitbang Kemendikbud \\ email: subijanto2012@gmail.com
}

\begin{abstract}
Abstrak: Penyelenggaraan program Pendidikan Menengah Universal dilatarbelakangi oleh keberhasilan program wajib belajar pendidikan dasar 9 tahun. Atas dasar itu, Kemendikbud perlu meningkatkan akses lulusan pendidikan dasar untuk melanjutkan ke pendidikan menengah melalui program wajib belajar 12 tahun. Tujuan penelitian ini dimaksudkan untuk mengkaji implementasi program Pendidikan Menengah Universal, terkait dengan (1) acuan legal formal; (2) kesiapan penyediaan sarana dan prasarana; (3) kesiapan penyediaan pendidik dan tenaga kependidikan; dan (4) kesiapan pendanaan. Metode penelitian yang digunakan adalah survei, dengan teknik pengambilan sampel secara purposive. Hasil studi menunjukkan bahwa: (a) semua daerah sampel belum memiliki acuan legal formal untuk melaksanakan program PMU; (b) ketersediaan sarana dan prasarana pembelajaran belum memadai; (c) ketersediaan pendidik dan tenaga kependidikan belum mencukupi dan pendistribusiannya belum merata; dan (d) ketersediaan pendanaan masih terbatas.
\end{abstract}

Kata kunci: pendidikan menengah universal, wajib belajar 12 tahun, sarana prasarana, pendidik dan tenaga kependidikan, pendanaan

\section{THE UNIVERSAL EDUCATION PROGRAM IN PREPARING FOR TWELVE YEARS COMPULSORY EDUCATION}

\begin{abstract}
The implementation of the universal education program for secondary school has been based on the success of the nine year primary compulsory education. Therefore, it is crucial for the Ministry of Education and Culture to improve the access for primary education graduates to secondary school through the twelve years compulsory education. The aim of this study is to analyze the implementation of the universal secondary education in relation to (1) the legal formal; (2) the provision of the educational infrastructure and facilities; (3) the provision and distribution of teachers and administration staff; and (4) the supporting fund. The method used was survey with purposive sampling technique. The results of the study are: (a) all sample areas have not had any legal basis supporting the implementation of universal education program for secondary education; (b) the educational infrastructure and facilities are not adequate (c) teachers and administration staff are insufficient and unevenly distributed; (d) operational budget is limited.
\end{abstract}

Key words: universal education program, twelve years compulsory education, educational facilities, teachers and administration staff, budgeting

\section{PENDAHULUAN}

Salah satu yang melatarbelakangi penyelenggaraan program Pendidikan Menengah Universal (PMU) adalah keberhasilan program wajib belajar (wajar) pendidikan dasar (dikdas) sembilan tahun. Keberhasilan program tersebut memiliki konsekuensi logis terhadap pemberian akses bagi anak usia sekolah lulusan pendidikan dasar untuk melanjutkan pendidikan ke jenjang pendidikan menengah.
Pemerintah telah menyatakan penyelenggarakan program wajar dikdas 9 tahun telah tuntas, namun pada kenyataannya program tersebut belum seluruhnya tuntas. Ketuntasan masih dalam taraf mengurangi angka melek huruf dan peningkatan angka partisipasi kasar (APK). Secara kualitatif, program dimaksud memang belum memenuhi kualitas dan secara kuantitatif kesuksesan tersebut baru ditunjukkan pada pencapaian APKSMP 97 persen (Muhammad, 2012:2); Kemendikbud, 2015:12). 
Dalam menetapkan ketuntasan wajar dikdas, Pemerintah menggunakan acuan tahapan pencapaian APK, yaitu (1) tuntas pratama, jika APK mencapai $80 \%$ s.d. $84 \%$; (2) tuntas madya, jika APK mencapai $85 \%$ s.d. $89 \%$; (3) tuntas utama, jika APK mencapai 90\% s.d. 94\%; dan (4) tuntas paripurna, jika APK mencapai minimal 95\% (Dir. Pembinaan SMP, 2008:6). Walaupun demikian, Pemerintah masih perlu menuntaskan wajar dikdas 9 tahun agar seluruh anak usia pendidikan dasar di Indonesia dapat menyelesaikan pendidikannya sampai tamat SMP/MTs.

Secara logis, keberhasilan wajar dikdas 9 tahun memiliki kesinambungan dengan penyelenggaraan program wajar 12 tahun. Namun, program tersebut belum dapat dilaksanakan karena belum memiliki dasar hukum yang kuat. Oleh sebab itu, Kemendikbud menetapkan program PMU sebagai kebijakan "rintisan" wajar 12 tahun yang sifatnya "anjuran" yang sangat diharapkan untuk dilaksanakan (sunnah muakadah). Selain itu, program tersebut bersifat "preparatif dan antisipatif" untuk menyongsong "bonus demografi" yang diperkirakan akan terjadi pada tahun 2020 sampai dengan tahun 2035.

Bonus demografi dapat dimaknai sebagai kesempatan untuk menikmati kesejahteraan masyarakat, dikarenakan potensi sumber daya manusia (SDM) sangat produktif menghasilkan barang/jasa kesehatan untuk keperluan masyarakat. Pergeseran distribusi umur penduduk dan penurunan rasio ketergantungan penduduk muda (youth dependency ratio) menciptakan keadaan ideal yang menghasilkan potensi terjadinya bonus demografi. Kondisi ideal ini menunjukkan jumlah penduduk usia kerja hampir dua kali lipat dibandingkan dengan jumlah penduduk di bawah 15 tahun (Adioetomo, 2005:23; Wongboonsin \& Patcharawalai, 2003:7; dan John Ross, 2004:1).

Terkait dengan hal tersebut, Djalal (2015:3) mengemukakan bahwa transisi demografi mengakibatkan adanya(1) proses transisi demografi yang disebabkan oleh penurunan fertilitas dan moralitas; (2) perubahan struktur umur penduduk, mencakup (a) penurunan fertilitas akan menurunkan proporsi penduduk usia muda, dan (b) penurunan mortaltitas akan meningkatkan harapan hidup, proporsi penduduk usia kerja dan lansia; dan (3) rasio ketergantungan penurunan karena penurunan proporsi penduk mudadan peningkatan proporsi penduduk usia kerja.
Adioetomo (2005:48) menyatakan perubahan struktur usia penduduk akibat transisi demografi jangka panjang bedampak pada "(1) peningkatan jumlah tenaga kerja yang apabila mendapatkan kesempatan kerja yang produktif akan meningkatkan total output; (2) penumpukan kekayaan yang lebih besar, apabila ada tabungan masyarakat yang diinvestasikan secara produktif; dan (3) tersedianya human capital yang jumlahnya lebih besar (dibandingkan waktu sebelumnya), sehingga apabila ada kebijakan investasi yang khusus diarahkan untuk meningkatkan kapasitas SDM, Indonesia akan memiliki peluang untuk menciptakan tenaga kerja tingkat menengah yang tangguh dan berkualitas untuk mengelola sumber daya alamnya".

Berdasarkan latar belakang di atas, permasalahan yang timbul adalah sejauh mana kesiapan pemerintah daerah dalam mengimplementasikan program PMU? Mengacu pada permasalahan tersebut,tujuan studi ini dimaksudkan untuk mengkaji kesiapan pemerintah daerah dalam menyelenggarakan program PMU sehingga ditemukan (1) ada tidaknya acuan legal formal penerapan penyelenggarakan program PMU; (2) kecukupan sarana dan prasarana pendidikan; (3) kecukupan pendidik dan tenaga kependidikan (PTK); serta (4) kecukupan penyediaan pendanaan operasional pendidikan.

Program PMU secara resmi telah di "launching" Mendikbud pada Juni 2013. Hal ini menandakan bahwa pada tahun pelajaran 2013/2014 Kemendikbud secara resmi mulai mengimplementasikan kebijakan tersebut. Pemberlakuan ini terutama bagi daerah yang telah menyatakan siap untuk melaksanakannya. Daerah dimaksud meliputi Provinsi (1) Daerah Istimewa Yogyakarta; (2) Jawa Timur; (3) Sumatera Selatan, (4) Sumatera Utara, (5) Jambi, (6) Bangka Belitung, (7) Lampung, (8) Bali; (9) Kalimantan Timur; (10) Kalimantan Selatan; (11) Sulawesi Selatan; (12) Sulawesi Utara, dan (13) Maluku.

Selaras dengan penyelenggaraan program PMU, Pemerintah telah mempertimbangkan Undang-Undang Republik Indonesia Nomor 13 Tahun 2009 tentang Tenaga Kerja (UU No.13/2009), bahwasannya lulusan SMP/MTs atau yang sederajat belum layak untuk bekerja. Oleh karena itu, apabila mereka tidak melanjutkan pendidikan ke sekolah menengah maka diasumsikan mereka akan memiliki dampak sosial yang lebih kompleks. 
Sambil menunggu acuan legal formal terkait dengan amanat penyelenggaraan program wajar dikmen 12 tahun, Pemerintah telah mengeluarkan acuan pelaksanaan program PMU melalui Peraturan Menteri Pendidikan dan Kebudayaan Nomor 80 Tahun 2013 tentang Pendidikan Menengah Universal.

Skema strategi pencapaian APK sekolah menengah mencapai 97 persen pada tahun 2020 ditunjukkan pada Gambar 1.

Pendidikan memiliki peran yang menentukan bagi kemajuan suatu bangsa. Peran pendidikan dimaksud antara lain dalam hal pembangunan daya saing bangsa, mengurangi kemiskinan, dan meningkatkan pertumbuhan ekonomi. Hal ini didukung adanya tren pertumbuhan ekonomi di Indonesia periode 2010-2014 cukup baik. Kondisi tersebut menimbulkan harapan Indonesia akan menjadi salah satu negara dengan kekuatan ekonomi terbesar di dunia (Kemendikbud, 2015:12-13). Peran penting pendidikan dalam pembangunan ekonomi, terutama dalam hal kemampuan Pemerintah menyediakan tenaga kerja terampil. Hal ini sejalan dengan prinsip bahwa pendidikan dapat memberikan kontribusi peningkatan produktivitas tenaga kerja sehingga berdampak pada meningkatnya penghasilan pekerja.

Namun, hal tersebut kurang didukung oleh hasil penelitian Slamet PH (2014:301-311) yang menunjukkan bahwa (1) peningkatan jumlah siswa SMK tidak mendukung pertumbuhan ekonomi dan (2) peningkatan jumlah siswa SMK menyebabkan tingkat pengangguran lulusan SMK makin tinggi.

McKinsey dari Global Institute (Kemendikbud, 2015: 13-14) memperkirakan pada tahun 2030 Indonesia membutuhkan tenaga kerja terampil sebanyak 113 juta orang sehingga akan menempatkan posisi Indonesia pada tujuh besar ekonomi dunia. Ia memperkirakan bahwa Indonesia akan menjadi negara dengan kekuatan ekonomi nomor tujuh di dunia pada tahun 2030 . Perkiraan ini berdasarkan pada tingkat pertumbuhan ekonomi Indonesia yang dinilai paling stabil di dunia (Kemendikbud, 2015:12-13). Apabila hal ini dikaitan dengan "bonus demografi", Indonesia harus memanfaatkan momentum "bonusdemografi" yang diperkirakan akan berlangsung mulai tahun 2020-2035. Hal ini ditandai dengan meningkatnya usia produktif dan menurunnya usia tidak produktif. Manakala kita tidak mampu meraih kesempatan tersebut, Indonesia akan kehilangan kesempatan (lost opportunity)emas dan bisa jadi kesempatan itu tidak akan dapat terulang kembali.

Untuk menjawab tantangan tersebut, salah satu kebijakan telah ditetapkan untuk meningkatkan wajib belajar dari 9 tahun menjadi 12 tahun yang diawali dengan pelaksanaan program PMU dengan target pencapaian APK sekolah menengah 97 persen pada tahun 2020. Harapan ketercapaian target tersebut, didukung hasil penelitian Putra (2015:iv) yang menyimpulkan bahwa pelaksana-

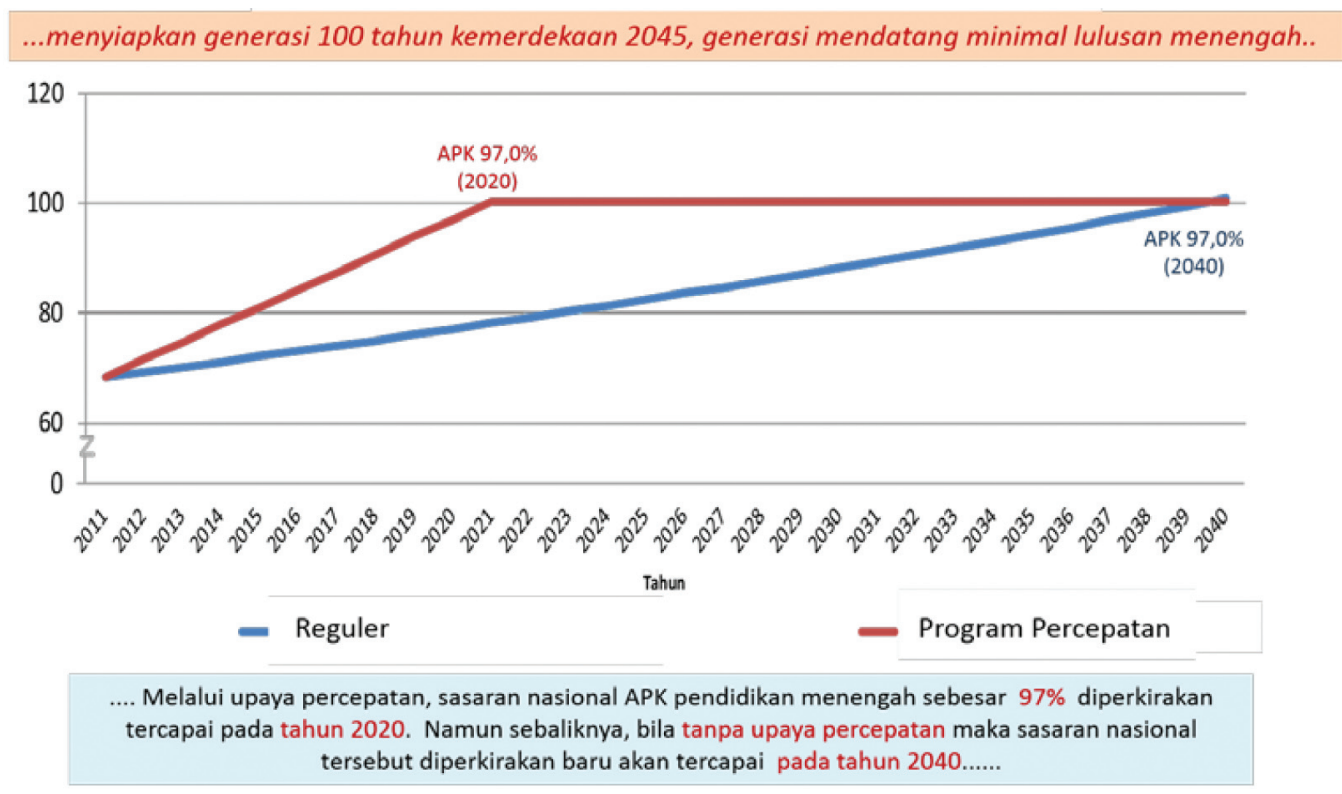

Gambar 1. Skema Strategi Pencapaian APK (Ditjen. Pendidikan Menengah,2012:31) 
an PMU di Provinsi Jawa Tengah diproyeksikan akan berhasil mencapai sasaran PMU mencapai 97 persen dan memperkecil disparitas APK antarkabupaten/kota pada tahun 2020. Namun, jika program PMU tidak dilaksanakan di seluruh wilayah NKRI mulai tahun 2013, maka harapan pencapaian APK 97 persen secara tuntas diprediksikan baru akan terwujud pada tahun 2040 (Gambar 1).

Keberlangsungan pelaksanaan PMU membawa konsekuensi pada dukungan anggaran yang cukup besar, sehingga diperlukan komitmen dan tanggung jawab bersama, tidak hanya dari Pemerintah Pusat, pemerintah daerah, dan masyarakat, namun dari seluruh para pemangku kepentingan pendidikan lainnya, termasuk pihak dunia usaha dan dunia industri (DUDI). Oleh karena itu, dalam penyelenggaraan PMU, perlu melakukan kerjasama antara Pemerintah dengan DUDI (khususnya untuk SMK).

\section{METODE}

Metode penelitian ini menggunakan metode survei untuk mengetahui ketercapaian implementasi PMU dilihat dari aspek ketersediaan legal formal, ketersediaan sarana dan prasarana, ketersediaan pendidik dan tenaga kependidikan serta sumber pendanaan. Penelitian ini menggunakan data sekunder dan data primer. Data sekunder diperoleh dari sumber Peta Kondisi PMU di daerah sampel yang dianalisis untuk mengetahui tingkat ketercapaian implementasi PMU dari berbagai aspek seperti ketersediaan sarana dan prasara, pendidik dan tenaga kependidikan, serta pendanaan (Kemendikbud, 2013). Data primer bersumber dari hasil isian kuesioner dinas pendidikan dan sekolah, digunakan untuk mengetahui kondisi saat ini dan perkembanagan implementasi PMU.

Populasi penelitian mencakup 10 kabupaten/kota dari provinsi yang menyatakan telah merintis program PMU. Pengambilan sampel dilakukan secara purposive. Penentuan teknik sampling secara purposif dilakukan dengan pertimbangan tertentu sesuai tujuan penelitian (Sugiyono, 2008:85). Pertimbangan dimaksud yaitu kesiapan sampel dalam mengimplementasikan program PMU.

Pemilihan sampel ditetapkan dengan kriteria kabupaten/kota yang telah (a) melaksanakan program PMU; (b) memiliki APK tinggi di atas rata-rata nasional $(>76,4 \%)$; dan (c) memiliki APK di bawah rata-rata nasional $(<76,4 \%)$. Studi ini melibatkan pejabat dinas pendidikan kabupaten/kota, Pejabat Bappeda/BKD, kepala bidang di lingkungan dinas pendidikan kabupaten/kota, kepala SMA, kepala SMK, dan kepala SMP, komite sekolah, dan staf DAPODIK sebgai responden. Teknik analisis data dilakukan dengan menggunakan statistik deskriptif sederhana dalam bentuk tabel dan grafik. Mendeskripsikan data kualitatif dan kuantitatif.

\section{HASIL DAN PEMBAHASAN}

Pertama, ketersediaan legal formal sebagai acuan implementasi program PMU di sepuluh daerah sampel belum ada aturan legal formalnya. Namun demikian, legal formal PMU secara implisit telah tercantum dalam "satu pasal" Perda Penyelenggaraan Pendidikan. Pemda yang telah mengaturnya yaitu Kodya Surabaya, Kabupaten Tanjung Jabung Timur, dan Kabupaten Belitung Timur.

Kepemiliklan legal formal terkait dengan pelaksanaan program PMU di 10 kabupaten/ kota sampel secara rinci dapat dicermati pada tabel 1 .

Tabel 1 mengindikasikan bahwa pemerintah daerah dan dinas pendidikan provinsi/kabupaten/kota belum siap melaksanakan program PMU pada tahun pelajaran 2013/2014. Hal ini disebabkan antara lain karena kesalahpahaman tentang pendidikan gratis dan program PMU yang terlebih dahulu telah diterapkan di kabupaten/ kota sampel.

Kedua, ketersediaan sarpras pembelajaran seperti UKB dan USB belum memadai. Pemda perlu memperhatikan rasio lulusan peserta didik SMP/MTs di daerahnya masing-masing. Jika rasio peserta didik per rombongan belajar belum sesuai dengan SNP, maka dapat dihitung rasio rombel terhadap kebutuhan ruang kelas. Penambahan USB dan RKB diperlukan untuk meningkatkan daya tampung satuan pendidikan menengah agar mampu menampung seluruh lulusan SMP/ MTs. Khusus pendirian USB, diamanatkan oleh Permendikbud Nomor 80 Tahun 2013 bahwa penyediaan USB dilakukan untuk menjamin tersedianya satu satuan pendidikan menengah di setiap wilayah kecamatan di Indonesia. 
Tabel 1. Kepemilikan Legal Formal PMU

\begin{tabular}{|c|c|c|}
\hline Kabupaten/Kota & Regulasi Penyelenggaraan Pendidikan & Keterangan \\
\hline Kabupaten Karangasem & $\begin{array}{l}\text { Perda Nomor } 5 \text { Tahun } 211 \text { tentang Sistem } \\
\text { Penyelenggaraan Pendidikan }\end{array}$ & $\begin{array}{l}\text { Belum memiliki perda pelaksanaan program } \\
\text { PMU. Wajar diberlakukan bagi setiap anak } \\
\text { usia } 7-15 \text { tahun (wajar dikdas). Belum ada } \\
\text { aturan yang secara spesifik mengatur } \\
\text { implementasi PMU }\end{array}$ \\
\hline Kota Surabaya & $\begin{array}{l}\text { Perda Nomor } 16 \text { Tahun } 2012 \text { tentang } \\
\text { Sistem Penyelenggaraan Pendidikan }\end{array}$ & $\begin{array}{l}\text { Mendukung pelaksanaan program PMU, } \\
\text { kewajiban belajar bagi setiap anak usia 7-18 } \\
\text { tahun. Memiliki Perwali tentang PMU } \\
\text { namun tidak secara detail mengatur } \\
\text { pelaksanaan program PMU }\end{array}$ \\
\hline Kota Makassar & $\begin{array}{l}\text { Memiliki Pergub.Sulsel Nomor } 9 \text { Tahun } \\
2014 \text { tentang Pelaksanaan Peraturan } \\
\text { daerah Provinsi Sulawesi Selatan. Pergub. } \\
\text { Nomor } 4 \text { Tahun } 2009 \text { tentang } \\
\text { Penyelengaraan Pendidikan Gratis. } \\
\text { Perda Kota Makassar Nomor.3 Tahun } \\
2006 \text { tentang Penyelenggaraan }\end{array}$ & $\begin{array}{l}\text { Mendukung pelaksanaan program PMU, } \\
\text { hanya pada klausul kebijakan yang mengatur } \\
\text { tentang penyeleng garaan pendidikan. } \\
\text { Pendidikan gratis diselenggarakan pada } \\
\text { jenjang pendidikan dasar dan menengah. } \\
\text { Tidak secara spesifik mengatur pada program } \\
\text { PMU }\end{array}$ \\
\hline
\end{tabular}

Pendidikan.

Keputusan Walikota Makassar Nomor.

4405/ 1006/Kep/2014 tentang Nama

Satuan Pendidikan Penyelenggara

Pendidikan Gratis

SMA/SMK/MA/SMALB Negeri/Swasta

se Kota Makassar Tahun Ang garan 2014

Kabupaten Tanjung Jabung Perda Nomor 16 Tahun 2013 tentang Timur Penyelenggaraan Pendidikan Gratis dan Berkualitas

Mendukung program PMU, namun tidak secara spesifik mengatur tentang program PMU, Wajib belajar dan pendidikan gratis dimulai pada jenjang SD hingga SMA

Kabupaten Belitung Timur Perda Nomor 10 Tahun 2011 tentang Sistem Penyelenggaraan Gratis dan Perda Nomor 5 Tahun 2011 tentang Kewenangan Pemerintahan Kabupaten Belitung Timur

Kabupaten OKU Selatan Peraturan Gubernur Sumatera Selatan dan Peraturan Bupati OKU Selatan tentang pendidikan/sekolah gratis

Kota Banjarmasin

Kabupaten Deli Serdang

Kabupaten Minahasa Utara

Kota Balikpapan
Perda Nomor 2 Tahun 2014 tentang Perubahan Atas Peraturan Daerah Kota Banjarmasin Nomor 13 Tahun 2009 tentang Penyelenggaraan Pendidikan

Memiliki Peraturan Gubernur Sumatera Utara dan Peraturan Daerah Kabupaten Deli Serdang tentang Wajib Belajar

Memiliki Perda Provinsi Minahasa Utara tentang Penyelenggaraan Pendidikan

Perda Provinsi Kalimantan Timur Nomor 3 Tahun 2010 tentang Penyelenggaraan Pendidikan
Mendukung pelaksanaan program PMU dengan penyelenggaraan program wajib belajar 12 tahun. Pemda berkewajiban menyelenggarakan pendidikan dasar dan menengah yang bermutu dan berkualitas Belum memiliki kebijakan yang langsung mengamanat kan tentang PMU.Namun, melalui kebijakan Pergub. Penyelenggaraan pendidikan mengarah pada dukungan terhadap pelak sanaan PMU.

Mendukung pelakasanaan program PMU, penyelengga raan pendidikan jenjang menengah menjadi tanggungjawab pemda dan masyarakat serta pembiaya annya ditanggung pemda dan masyarakat.

Belum mendukung pelak sanaan program PMU. Kewajiban belajar untuk setiap anak usia 7-15 tahun. Belum ada peraturan yang secara spesifik mengatur pelaksanaan program PMU.

Mendukung pelaksanaan program PMU. Semua anak usia sekolah wajib belajar dan menyelesaikan pendi dikan minimal SLTA (wajar 12 tahun) dan memiliki keterampilan serta mengu asai teknologi informasi dan bahasa asing.

Mendukung pelaksanaan program PMU, dan dalam Perda telah dinyatakan Wajib belajar 12 tahun.

Sumber : Data diolah 


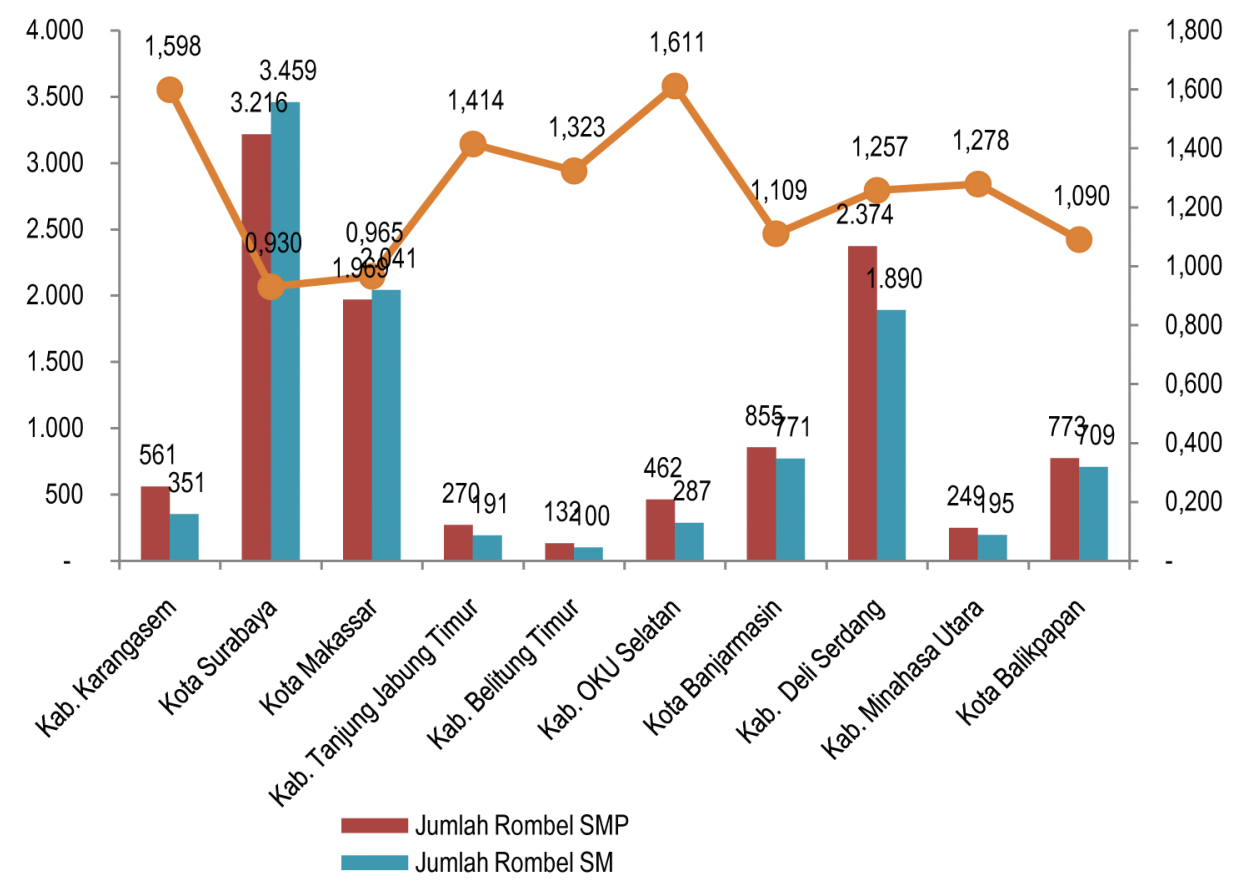

Grafik 1. Ketercukupan Sarana dan Prasarana (RKB) Sumber: Data diolah

Dengan memperhatikan matrik analisis rasio kecukupan ruang kelas, berdasarkan analisis rasio jumlah lulusan SMP/MTs terhadap ketersediaan rombongan belajar (rombel) di Kelas X SM saat dilakukan penelitian, hampir seluruh kabupaten/kota daerah sampel dengan rasio rombel $>$ 1 (kecuali Kodya Surabaya dan Makassar) masih membutuhkan tambahan rombel (perlu tambahan RKB) untuk menampung 100 \% lulusan SMP/ MTs masuk ke sekolah menengah.

Hasil DKT menegaskan bahwa kebijakan penambahan RKB-USBditetapkan dinas pendidikan dan pemangku kepentingan lainnya terkait penyelenggaraan PMU didasarkan pada perkiraan kebutuhan dan kondisi sarpras saat ini dengan memprediksi kebutuhan yang akan datang berdasarkan lulusan SMP/MTs. Dalam hal pemenuhan USB, sebagian besar daerah sampel belum mencukupi sesuai tuntutan Permendikbud 80 tahun 2013 tentang PMU Pasal 4 ayat (5) dan Peraturan Menteri Pendidikan Nasional No. 24 Tahun 2007 tentang Standar Sarana dan Prasarana Pendidikan. Berdasarkan data kabupaten/kota sampel, masih ada tiga kabupaten yang belum memiliki sekolah menengah (SM) di kecamatan yaitu Kabupaten Belitung Timur, Kabupaten OKU Selatan dan Kabupaten Minahasa Utara. Dengan demikian, prioritas penyediaan USB SMA/MA/ SMK atau UGB SMP-SM satu atap yaitu di kecamatan-kecamatan tersebut. Ini berarti belum semua kabupaten memenuhi Permendikbud No. 80 Tahun 2013.

Keberadaan sarana dan prasarana, khususnya RKB dan USB telah memberikan kontribusi yang posistif dalam meningkatkan mutu pendidikan. Pada grafik dibawah ini menunjukkan pendapat kepala sekolah sampel menyatakan bahwa peningkatan sarana dan prasarana telah memberikan efek yang positif terhadap beberapa aspek, yaitu (a) pembelajaran menjadi efektif (80\%); (b) pembelajaran dapat dilaksanakan pada pagi hari $(65 \%)$; (c) peserta didik akan lebih mudah mencerna pembelajaran jika pembelajaran tersebut dilaksanakan pada pagi hari: (d) peserta didik tidak perlu bergantian menggunakan ruang kelas; dan (e) setiap rombel dapat menempati ruang kelasnya masing-masing.

Ketiga, pendidik dan tenaga kependidikan merupakan faktor kunci dalam penyelenggaraan proses pembelajaran pada satuan pendidikan. Sesuai amanat Undang-Undang Guru dan Dosen, setiap pengadaan guru baru harus memiliki kualifikasi minimal S1/D4 (UU No.14/2005). Kebijakan ini untuk menjaga agar implementasi PMU tidak berdampak pada penurunan jumlah guru yang berkualifikasi pendidikan S1/D4 akibat dari mengejar ketersediaan jumlah guru. Kebijakan terkait PTK dalam penyelenggaraan PMU antara lain merencanakan pemenuhan kebutuhan guru sesuai dengan jumlah dan jenis guru (guru kelas, 


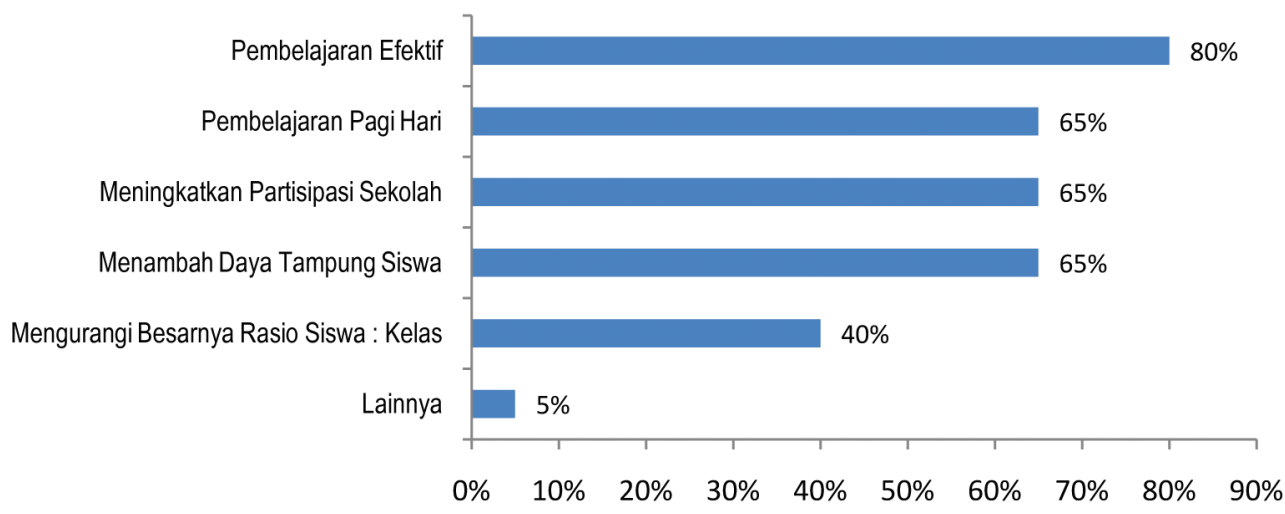

Grafik 2. Kontribusi Peningkatan Sarana dan Prasarana

Sumber: Data diolah

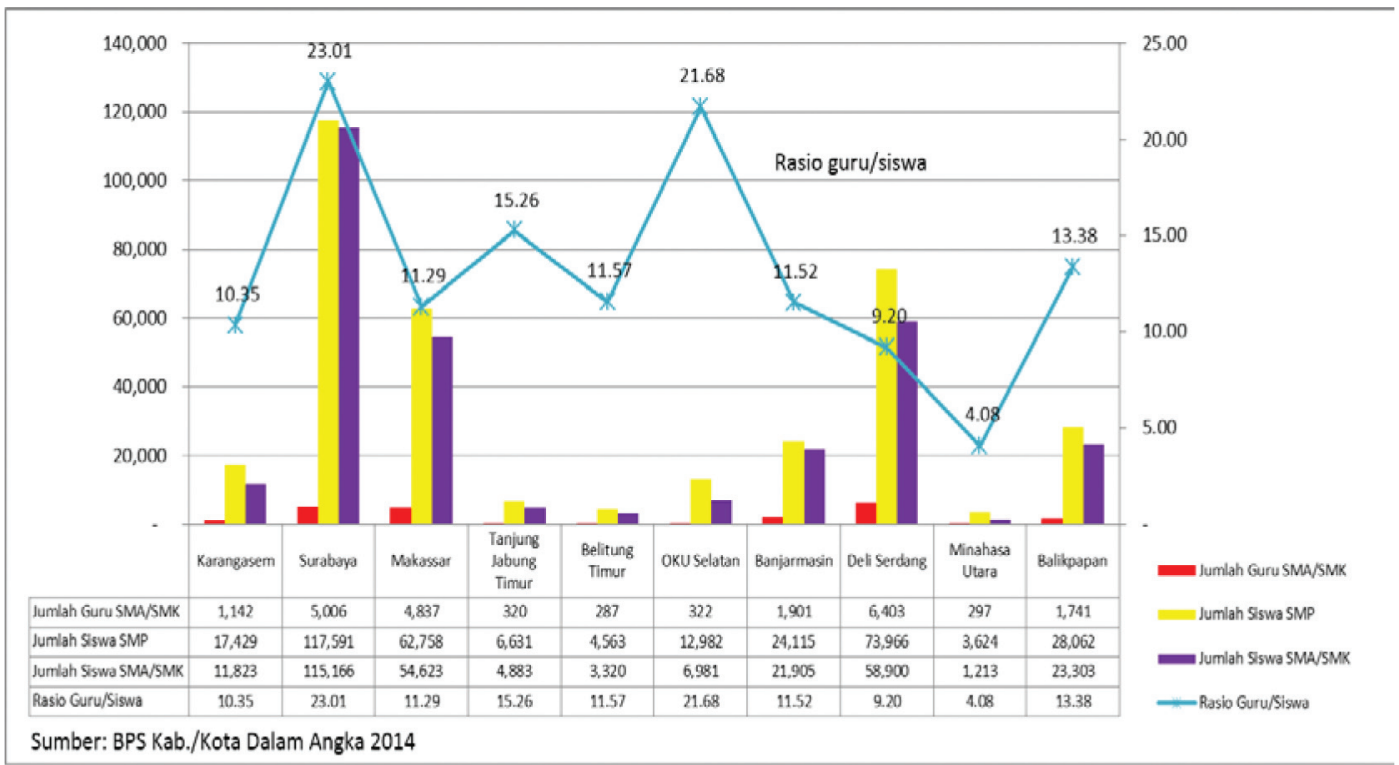

Grafik 3. Rasio Guru : Peserta didik

Sumber: Data diolah

guru mata pelajaran, di SMA dan guru produktif di SMK). Kekurangan guru pada saat ini dipenuhi dengan cara merekrut guru honorer yang diangkat oleh kepala sekolah.

Grafik 3 menunjukkan ketercukupan guru di Kabupaten Karangasem, Kota Makassar, Kabupaten Tanjung Jabung Timur, Kabupaten Belitung Timur, Kota Banjarmasin dan Kota Balikpapan

Keempat, ketersediaan pendanaan penyelenggaraan PMU. Kondisi ekonomi di suatu wilayah memberikan gambaran tentang potensipotensi unggulan yang dapat dijadikan referensi untuk meningkatkan akses pendidikan menengah sesuai atau relevan dengan kebutuhan suatu wilayah. Di samping potensi wilayah, kondisi ekonomi wilayah dibutuhkan untuk memberikan gambaran kemampuan daerah dan masyarakat dalam menyediakan pendidikan yang berkualitas bagi seluruh masyarakat.
Kemampuan daerah yang dimaksud dalam studi ini terfokus pada kemampuan fiskal dan masyarakat. Kapasitas fiskal merupakan gambaran kemampuan keuangan masing-masing daerah yang dicerminkan melalui penerimaan umum APBD untuk membiayai tugas pemerintahan setelah dikurangi belanja pegawai dan dikaitkan dengan jumlah penduduk miskin. Penerimaan APBD tidak termasuk dana alokasi khusus (DAK), dana darurat, dana pinjaman lama, dan penerimaan lain yang penggunaannya dibatasi untuk membiayai pengeluaran tertentu.

Pada jenjang pendidikan menengah, sumber dana provinsi dialokasikan untuk (a) peningkatan mutu manajemen, profesi guru dan penyusunan kurikulum melalui Bimtek dan MGMP; (b) pembelian buku referensi muatan lokal; (c) pembiayaan panitia ujian dan laporan hasil prestasi peserta didik; (d) kegiatan pembe- 
lajaran, remedial, dan pengayaan; (e) pembiayaan penerimaan peserta didik baru (PSB); (f) insentif tenaga kependidikan; dan (g) pembiayaan operasional kantor.

Pendanaan urusan bersama Pusat dan daerah untuk penanggulangan kemiskinan sesuai dengan PMK Nomor 74/PMK.07/2013 digunakan dua indikator yaitu Indeks Ruang Fiskal Daerah (IRFD) yang merupakan indikator kekuatan pendanaan keuangan daerah dan Indek Persentase Penduduk Miskin Daerah (IPPMD) untuk mengukur tingkat kemiskinan daerah.

Hasil DKT mengindikasikan bahwa beberapa daerah telah berupaya mengalokasikan dana untuk pengadaan sarana dan prasarana PMU yang bersumber dari dana APBD untuk pembelian tanah guna pembangunan USB, sedangkan dana pembangunannya bersumber dari Pemerintah Pusat dan dana yang bersumber dari APBD provinsi/kabupaten/kota. Namun, dana dari APBD kabupaten/kota sangat terbatas baik untuk pembangunan USB, RKB maupun pembangunan laboratorium dan perpustakaan. Grafik berikut menggambarkan alokasi anggaran pendidikan melalui APBD serta persentase alokasi anggaran pendidikan.

Kebijakan penganggaran pelaksanaan PMU di daerah secara eksplisit belum sepenuhnya mengatur tentang pembiayaan PMU. Hasil temuan dilapangan berdasarkan instrumen yang disampaikan kepada kepala dinas kabupaten/kota sampel menyebutkan bahwa kebijakan pembiayaan penyelengaraan PMU tidak diatur secara khusus (30\%) namun mengikuti aturan kebijakan kepala daerah setempat (20\%).
Penggunaan DAK hanya dimungkinkan untuk pembangunan RKB manakala penambahan ruang dibangun secara 'vertikal'. Dalam kaitannya dengan program PMU,pembangunan sarana prasarana dimungkinkan melibatkan peran serta masyarakat, selain Pemerintah dan pemerintah daerahsesuai dengan Permendikbud No. 80/2013 tentang PMU.

Kota Balikpapan, pendanaan PMU dalam konteks Wajar 12 Tahun mendapat dukungan yang sangat besar dari APBD Kota maupun APBD provinsi. Hal ini terlihat dari alokasi bantuan operasional sekolah (BOS) dari Pemda dan dari Provinsi sebagai tambahan BOS dari Pusat. Sekolah menengah pertama (SMP) di Kota Balikpapan mendapatkan subsidi tambahan dari APBD kota (BOSDA) sebesar Rp1.000.000/peserta didik/tahun. Dari BOS Provinsi (BOSPROV) diterimakan sebesar 2.000.000/peserta didik/tahun (SMA) dan RP 2.500.000/peserta didik/tahun (SMK). Selain bantuan BOS tersebut, masih ada bantuan lain bagi peserta didik miskin dan siswa berprestasi "Kaltim Cemerlang".

Upaya yang dilakukan Pemda Kodya Makassar untuk biaya pengadaan sarana/prasarana PMU, antara lain bersumber dari dana APBD dengan menyediakan tanah untuk pembangunan USB, sedangkan dana pembangunannya bersumber dari Pemerintah Pusat (Dirjen. Pendidikan Menengah) didukung dana bersumber dari APBD Provinsi Sulsel. Namun, dana dari APBD Kodya Makassar sangat terbatas baik untuk pembangunan USB, RKB maupun pembangunan Laboratorium dan Perpustakaan.

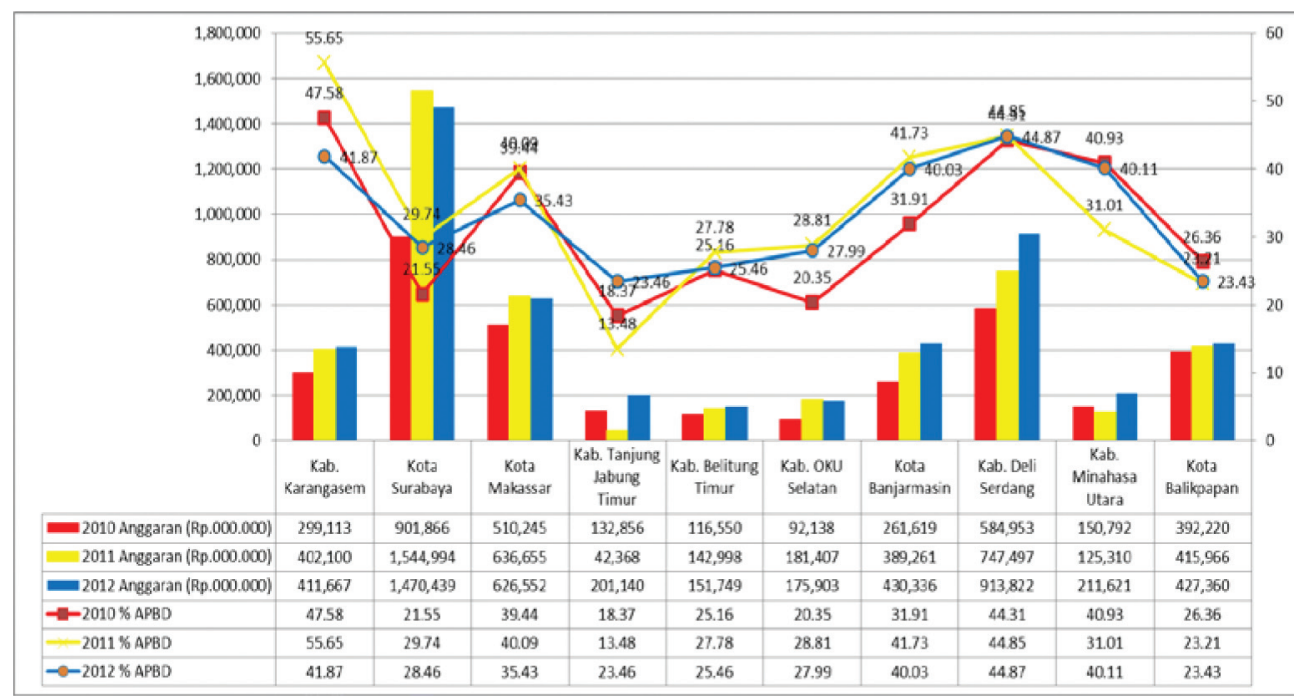

Grafik 4. Alokasi Anggaran Pendidikan

Sumber: Data diolah 
Untuk memenuhi kebutuhan biaya operasional sekolah, antara lain bersumber dari BOS APBN dan dana pendidikan gratis Provinsi dan Kodya Makassar. Dari sumber BOS APBN, masing-masing peserta didik memperoleh bantuan dana sebesar Rp1.000.000,-/tahun/peserta didik, sedangkan dana yang bersumber dari program pendidikan gratis Provinsi Sulsel dan Kodya Makassar seluruhnya berjumlah Rp 300.000/tahun/peserta didik. Dana pendidikan gratis tersebut dialokasikan 40\% dari Pemda Provinsi Sulsel dan $60 \%$ dari Kodya Makassar.

Walikota Makassar memberikan tambahan biaya khusus pada tiga SMAN di pinggiran kota Makassar yang populasi peserta didiknya kebanyakan dari keluarga miskin yang diharapkan akan terus bersekolah tanpa tinggal kelas dan putus sekolah. Selain memperoleh bantuan BOS APBN dan dana pendidikan gratis, sekolah tersebut juga memperoleh tambahan biaya pendidikan untuk peserta didik berupa uang transpor, pembelian buku, seragam sekolah dan ATK.

Berbagai sumber pendanaan tersebut diarahkan agar seluruh peserta didik lulusan SMP/ MTs sederajat dapat mengenyam pendidikan sampai lulus SM dengan gratis, sehingga APK di Kodya Makassar meningkat dan pada gilirannya dapat mendukung kebijakan PMU. Selain itu, dari dana APBN, beberapa peserta didik di sekolah tertentu juga memperoleh dana BSM yang dialokasikan untuk biaya pribadi peserta didik (kurang mampu) untuk keperluan transpor sehingga mereka akan tetap sekolah tanpa terkendala masalah biaya sekolahnya.

Hasil DKT menunjukkan bahwa sosialiasasi program PMU belum dilakukan secara menyeluruh kepada para pemangku kepentingan pendidikan. Hal ini diperkuat oleh persepsi daerah terhadap program PMU yang masih berbeda-beda. Walaupun pemahaman daerah terhadap program PMU berbeda-beda, akan tetapipada hakikatnya sama dengan pelaksanaan program pendidikan gratis di daerah masing-masing. Di samping itu, grand design PMU dan Peta Kondisi PMU masing-masing provinsi/kabupaten/kota yang semestinya dijadikan acuan pokok perencanaan, pelaksanaan, dan evaluasi program PMU belum disosialisasikan ke daerah secara tuntas.

Purwanto dan Sulistyastuti (2012:10) mengemukakan bahwa faktor kurangnya sosialisasi program PMU ini analog dengan program kebijakan dari Pemerintah Pusat ke daerah yang sering mengalami keterbatasan/kurang memadai dalam pelaksanaan sosialisasi program secara bertahap dan berkelanjutan.

Selain permasalahan sosialiasai program PMU, beberapa permasalahan pokok yang dihadapi dalam pelaksanaan program PMU, antara lain(1) wajar dikmen 12 tahun belum memiliki dasar hukum yang kuat baik Undang-Undang maupun Peraturan Pemerintah sebagai penyertanya; (2) Kesiapan pemerintah daerah dalam melaksanakan program PMU belum mengacu pada rencana induk (grand design) PMU yang disiapkana oaleh Dirjen Pendidikan Menengah (2012) dan Peta Kondisi Pendidikan Menengah Universal Kemendikbud (2013) yang mencakup seluruh kebutuhan komponen yang diperlukan termasuk aspek pendanaannya; (3) Persepsi daerah untuk melaksanakan program wajar 12 tahun cukup beragam dan belum diikuti dengan perencanaan infrastruktur yang memadai; dan (4) Pemerintah daerah yang telah menyatakan melaksanakan program wajar 12 tahun sebagai wujud otonomi pendidikan daerah belum memiliki komitmen yang menjamin keberlangsungan (sustainability) pelaksanaan program PMU.

Program PMU sebagai persiapan program wajar 12 tahun merupakan salah satu kebijakan yang mempresentasikan dukungan Pemerintah dan pemerintah daerah terhadap pendidikan. Wajib belajar secara langsung maupun tidak langsung akan berdampak pada investasi yang harus dikeluarkan oleh para pemangku kepentingan pendidikan (stakeholders)

Pembiayaan merupakan salah satu persoalan dalam pemerataan akses pendidikan.Oleh karena itu, salah satu kebijakan strategis Kemendikbud untuk pemerataan akses pendidikan yaitu menghapus hambatan biaya (cost barriers) melalui pemberian bantuan operasional sekolah (BOS) bagi semua siswa pada semua jenis dan jenjang pendidikan.Oleh karena itu, investasi pendidikan pada tingkat menengahharus dipenuhi sesuai dengan kebutuhannya sehingga wajib belajar dapat menghasilkan kualitas lulusannya yang bermutu.

Penelitian yang relevan dengan kajian PMU antara lain sebagai berikut. Kajian Connell (2003:235-250) tentang “Working-Class Families and the New Secondary Education" di Australia menunjukkan bahwa keluarga kelas pekerja umumnya lebih peduli agar anak-anak mereka masuk ke pendidikan menengah kejuruan sehingga mereka cepat bekerja. 
Penelitian Hu, Anning (2013:14-20) tentang "Proliferation of educational credentials, changing economic returns, and rising occupational education requirements: Evidence in urban China from 2003 to 2008 menunjukkan bahwa terjadi penurunan signifikan dalam keuntungan ekonomi untuk kemampuan perguruan tinggi, tetapi tidak ada perubahan signifikan dari keuntungan ekonomi untuk kemampuan pendidikan menengah.

Hasil kajian Crittenden (1988:287-310) tentang "Policy Directions for Australian Secondary Schools: A Critique of Some Prevalent Assumptions" menyimpulkan bahwa (1) setelah 15 tahun pemerintah menerapkan kebijakan terhadap pendidikan menengah, perlu perubahan dan pengambilan kebijakan baru oleh badan-badan pemerintah dalam praktik di sekolah memengah; (2) sekolah sebagai instrumen kesejahteraan ekonomi, cita-cita partisipasi universal sampai akhir sekolah menengah, dan program umum dari pendidikan umum untuk seluruh sekolah menengah sangat diperlukan masyarakat; dan (3) kemauan politik dari pemangku kepentingan turut andil besar dalam menentukan kebijakan pendidikan

Penelitian Banerji dan Anit (2008:213228) tentang pendidikan dasar di India berjudul "Achieving Universal Elementary Education in India: Future Strategies for Ensuring Access, Quality and Finance" menyimpulkan bahwa selama lima tahun, Sarva Shiksha Abhiyan (SSA) berhasil meningkatkan infrastruktur, menjamin akses, membawa out-of-shool ke dalam sistem pendidikan umum dan pengangkatan guru serta kualitasyang saling terkait. Prestasi belajar anak dapat ditingkatkan secara signifikan melalui strategi yang tepat akibat dampak pelatihan guru dan kegiatan remedial. Dalam hal anggaran untuk meningkatkan kualitas pendidikan dasar harus dipastikan melalui kombinasi kebijakan fiskal, strategi desentralisasi dan mekanisme implementasi yang baru.

Terkait dengan kebijakan pendidikan menengah gratis di Afrika Timur, hasil kajian Oketch et al., (2007:131-158) berjudul" Chapter 5 Policies on Free Primary and Secondary Education in East Africa: Retrospect and Prospect" dalam perumusan kebijakan untuk akses pendidikan dasar dan menengah di Kenya, Uganda, dan Tanzania menunjukkan bahwa beberapa negara di sub-Sahara Afrika pada umumnya kembali menerapkan pendidikan dasar gratis (FPE). Kebijakan tersebut sejalan dengan Education For All (EFA) dan Millennium Development Goals (MDGs).

\section{SIMPULAN}

Atas dasar temuan studi, dapat disimpulkan sebagai berikut. Pertama, secara umum penyelenggaraan program PMU belum memiliki dasar hukum yang kuat, dan secara khusus seluruh daerah sampel belum menggunakan acuan Permendikbud Nomor 80 Tahun 2013 tentang PMU. Namun demikian, beberapa daerah melalui peraturan daerah (Pergub/Perbup/Perwali secara implisit telah ada pasal yang mengatur program PMU. Persepsi daerah terhadap PMU lebih dimaknai sebagai pendidikan gratis yang mengarah pada program wajib belajar 12 tahun tanpa pungutan biaya.

Kedua, hampir seluruh daerah sampel masih membutuhkan tambahan sarana (USB/ RKB), Terdapat tiga kabupaten yang kecamatannya belum memiliki USB-SM; dua kabupaten yang tiga kecamatannya belum memiliki USBSM, dan satu kabupaten yang dua kecamatannya belum memiliki USB-SM.

Ketiga, kebutuhan pendidik dan tenaga kependidikan (PTK) di setiap daerah sampel sangat bervariasi, sebagian besar rasio guru terhadap peserta didik belum terpenuhi di setiap daerah sampel. Pemenuhan penyediaan dan pendistribusian PTK masih belum sesuai dengan jumlah dan jenis guru (seperti guru kelas, guru mata pelajaran, dan guru produktif SMK). Untuk sementara ini, kekurangan guru sebagian besar telah ditanggulangi oleh sekolah dengan merukrut guru honorer yang diangkat oleh kepala sekolah.

Keempat, penyediaan sumber pendanaan, sekalipun beberapa daerah memiliki nilai PDRB dan kemampuan fiskal yang rendah, akan tetapi dalam perkembangannya dari tahun 2010 hingga 2014 penganggaran fungsi pendidikan dana APBD terus meningkat. Seluruh kabupaten/kota telah menyediakan anggaran pendidikan yang bersumber dari dana APBD berupa BOSDA, kecuali Kabupaten Karangasem Provinsi Bali. Namun, secara keseluruhan sumber pendanaan untuk keperluan penyelenggaraan PMU belum mencukupi dan memerlukan tambahan dana yang bersumber dari APBN dan sumber lainnya yang tidak mengikat. 


\section{UCAPAN TERIMA KASIH}

Tim peneliti studi program PMU menyampaikan ucapan terima kasih, khususnya kepada Bagian Perencanaan Sekretariat Direktorat Jenderal Pendidikan Menengah yang telah memfasilitasi data sekunder terkait dengan "Peta Kondisi Pendidikan Menengah Universal" di seluruh kabupaten/kota di Indonesia. Ucapan terima kasih disampaikan pula kepada Ketua Redaktur dan staf Jurnal Cakrawala Pendidikan yang telah bersedia menerbitkan artikel ini.

\section{DAFTAR PUSTAKA}

Adioetomo. S.M.S. 2005. Bonus Geografi: Menjelaskan Hubungan antara Pertumbuhan Penduduk dengan Pertumbuhan Ekonomi. Pidato Pengukuhan Guru Besar Tetap Dalam Bidang Ekonomi Kependudukan, Fakultas Ekonomi Universitas Indonesia, Jakarta, 30 April 2005.

Banerji, R \& Anit N. 2008. "Achieving Universal Elementary Education in India: Future Strategies for Ensuring Access, Quality and Finance" dalam Margin: The Journal of Applied Economic Research, II (2),hlm. 213-228.

Connell, R. W. 2003. "Working-Class Families and the New Secondary Education", dalam Australian Journal of Education, XLVII (3), hlm.235-250.

Crittenden, B. 1988. "Policy Directions for Australian Secondary Schools: A Critique of Some Prevalent Assumptions", dalam Australian Journal of Education, XXXII (3), hlm.287-310.

Direktorat Pembinaan SMP. 2008. Panduan Pelaksanaan Sosialisasi Wajib Belajar 9 Tahun yang Bermutu, Jakarta: Depdiknas.

Direktorat Jenderal Pendidikan Menengah. 2012. Grand Design Pendidikan Menengah Universal, Jakarta: Dikdasmen.

Djalal.F. 2015. Bonus Demografi: Berkah atau Bencana, disampaikan pada Dialog Bonus Demografi, DDI, di Jakarta tanggal 2 September 2015.
Hu, A. 2013. Proliferation of Educational Credentials, Changing Economic Returns, and Rising Occupational Education Requirements: Evidence in Urban China from 2003 to 2008. dalam International Sociology, II (4),hlm. 448-466.

John. R. 2004. Understanding the Demographi Dividen.Policy Project,http://www.policyproject.com/policy/generalReport/ demo-div.pdf, Septem-ber 2014 diunduh 16 Maret 2015.

Kementerian Pendidikan dan Kebudayaan, 2013. Peta Kondisi Pendidikan Menengah Universal, Jakarta: Direktorat Jenderal Pendidikan Menengah.

Kementerian Pendidikan dan Kebudayaan, 2015. Rencana Strategis Kementerian Pendidikan dan Kebudayaan Tahun 2015 - 2919, Jakarta:Kemendikbud.

Muhammad, H. 2012. Pendidikan Menengah Universal. Makalah disampaikan pada Seminar Studi Pendidikan Menengah Universal, di Jakarta tanggal 3 Juni 2014.

Oketch, Moses, Rolleston \& Caine, 2007. "Policies on Free Primary and Secondary Education in East Africa: Retrospect and Prospect" dalam Review of Research in Education, XXXI(1),hlm. 131-158.

Peraturan Menteri Pendidikan dan Kebudayaan Nomor 80 Tahun 2013 tentang Pendidikan Menengah Universal.

Putra, S. 2015. Analisis Peran Program Menengah Universal Terhadap Peningkatan Partisipasi Masyarakat Dalam Pembangunan Pendidikan dan Pemerataan Distribusi Pendidikan di Jawa Tengah, Skripsi tidak diterbitkan, Semarang: PPS FEB, UNDIP.

Purwanto, A.E., dan Sulistyastuti , R.D. 2012. Implementasi Kebijakan Publik: Konsep dan Aplikasinya di Indonesia, Yogyakarta: Penerbit Gava Media.

Slamet PH. 2013. "Konstribusi Kebijakan Peningkatan Jumlah Siswa SMK terhadap 
Pembangunan Ekonomi Indonesia" dalam Cakrawala Pendidikan, Jurnal Ilmiah Pendidikan, hlm.301-31.

Sugiyono, 2008. Metode Penelitian Kuantitatif Kualitatif dan $R \&$ D , Bandung: CV ALFABETA.
Wongboonsin, K. \& Patcharawalai, W. 2003. First and Second Demographic Dividend, Thailand: Chulalongkorn University. 